\title{
PRACTICE
}

\section{Undergraduate Research in High-Altitude Ballooning at an Urban Community College}

\author{
Thomas B. Higgins, Harold Washington College \\ Bernhard Beck-Winchatz, DePaul University \\ Michael Davis, St. Petersburg College \\ Andrew Kruger, Wilbur Wright College
}

\begin{abstract}
The authors describe an undergraduate research program at the City Colleges of Chicago (CCC) organized around high-altitude ballooning and carried out primarily in an open, maker-space environment. Two cohorts of students were recruited. They undertook projects in biology, chemistry, engineering, environmental science, and physics. Via the Undergraduate Research Student Self-Assessment, both cohorts reported positive gains. The 2016 cohort was assessed immediately after the program ended, and the 2015 cohort was assessed one year afterward, suggesting the benefits of the program persisted for at least a year. Longitudinal data showed that the students completed degrees or transferred at rates higher than the general CCC student population. These data indicate that students benefited from their experiences and developed identities as scientists and engineers.
\end{abstract}

Keywords: community college, maker space, space grants, underrepresented students, workforce skills

\section{doi: 10.18833/spur/1/3/14}

In 2015, City Colleges of Chicago (CCC) was awarded a grant for undergraduate research and student scholarships from NASA Education and the Illinois Space Grant Consortium (ISGC). The project had two overarching goals: to engage community college students in undergraduate research involving high-altitude ballooning (HAB) and to support students with academic-year scholarships so they could pursue STEM degrees full time. The grant provided $\$ 500,000$ over a two-year period. Almost half of the funds directly supported students with scholarships and stipends, and the remainder bought supplies and faculty time. Although most project activities took place at $\mathrm{CCC}$, the project was an active collaboration between CCC and DePaul University, with the University of Illinois at Urbana-Champaign acting as the fiscal agent on behalf of the ISGC. The four coauthors of this article were the principal leaders of the project. Overall, 34 community college students and 8 other community college faculty members actively participated.

The largest community college system in Illinois, CCC consists of seven independently accredited colleges with six satellite sites. It serves more than 115,000 students annually with college credit, continuing education, and adult education programs. During the 2015-2016 academic year, approximately 62,000 full- and part-time students enrolled in college credit courses. This student body was ethnically diverse, self-reporting as 44 percent African American, 29 percent Hispanic, 17 percent White, and 6 percent Asian. The student body was 61 percent female and 39 percent male. Approximately 75 percent received some form of federal and/or state financial aid.

CCC students were engaged in HAB research with the hope that they would develop scientific literacy, positive affect, and academic success in STEM fields. The choice of undergraduate research as a pedagogical approach was grounded in personal experiences (discussed below) and the findings of others. Kuh (2008) has identified undergraduate research as a high-impact practice, and the many benefits of undergraduate research for students, faculty, 
and institutions have been collected in two reports of the National Academies of Science, Engineering, and Medicine (2015, 2017). Importantly, the 2017 National Academies report outlines a research agenda for undergraduate research, to which this article may contribute.

The program was specifically designed to foster student ownership by providing both the space and the flexibility for students to develop their projects and experiments. It was important that students thought of themselves as scientists and engineers and that they experienced the challenges of failure and the thrills of success that come with practicing authentic science. To promote this, students were encouraged to choose projects that touched multiple STEM disciplines. They analyzed data using mathematical and visualization tools and were allowed to make continuous refinements and improvements to their work. Students also were responsible for taking ownership of HAB flight planning, operations, and recovery, which forced them to plan ahead and to think on their feet. An institutional benefit was that the project promoted and strengthened the relationships among CCC, DePaul, and other ISGC members. Strong institutional relationships are essential to promote student graduation and transfer from the community college to the four-year institution or into the workforce (Higgins et al. 2011).

This article discusses engaging community college students in research, shares stories of student successes gathered through observations and assessment activities, and summarizes the lessons learned. Like most undergraduate research programs, there were challenges with respect to student and faculty time, institutional space and infrastructure, and supplies and materials to support the work. The funding was a major resource, but strong administrative support, faculty buy-in, and-most important-two outstanding cohorts of students who took their projects in unanticipated directions were significant contributors.

\section{Prior Work with Community College Students and Undergraduate Research}

Two CCC co-investigators, Higgins and Davis, had substantial experience leading undergraduate research initiatives with community college students. This provided an important resource to draw on for this project. For Higgins, this was an NSF-funded Undergraduate Research Collaborative (URC) award, "Exploring New Models for Authentic Undergraduate Research with Two-Year College Students" (Higgins 2013). The URC project built a network of 10 Chicago-area community colleges and three regional baccalaureate-granting institutions around academic-year and summer undergraduate research. During the five years of the URC project, 286 community college students participated in undergraduate research in both two-year and four-year college settings, and 96 percent of students successfully completed the program.
Davis was a co-principal investigator on an NSF-funded Science, Technology, Engineering, and Mathematics Talent Expansion Program award for the Chicago Initiative for Research and Recruitment in Undergraduate Science (CIRRUS). This project was a partnership between CCC and DePaul University. CCC students were placed into groups of six to eight with a single faculty mentor. These groups participated in a six-week summer program and pursued structured exercises regarding data analysis, scientific writing, and research ethics. They also developed research projects that could be completed in a short time period. Students were paid for up to 30 hours a week. Both the URC and CIRRUS projects were successful in recruiting diverse sets of community college students, engaging them in authentic undergraduate research, and facilitating their degree completion and/or transfer to a four-year institution.

Based on this prior work, the funding limitations, and time and institutional constraints, it was decided to pursue the HAB research activities during CCC's eight-week summer session. In summer 2015 and summer 2016, cohorts of 18 and 20 students, respectively, were invited to pursue research on a full-time basis in an open, maker-space setting, the HAB-Lab. The HAB-Lab was dedicated to the ballooning project, which gave students a private and professional space to develop and test their experiments and build their balloon payloads. At CCC, the HAB-Lab turned an underutilized physical science lab into one of the most vibrant spaces at the college (Higgins et al. 2017).

Each student who successfully completed the summer program received a full-time scholarship for tuition and fees and a stipend for textbooks. If a student maintained good academic standing, the scholarship was continued until graduation or transfer from CCC. Other CCC faculty participated in the project on a part-time basis by giving targeted lectures related to students' projects and making themselves available as consultants in their areas of expertise.

\section{Multidisciplinary Undergraduate Research with High-Altitude Ballooning}

$\mathrm{HAB}$ is the easiest and most cost-effective way to access Earth's stratosphere and near-space environment (Verhage 2004). Near-space is commonly defined as the region of Earth's atmosphere between $20 \mathrm{~km}$ and $100 \mathrm{~km}$ above sea level (see Figure 1). In this environment, balloons and their payloads are exposed to temperatures as low as $-60{ }^{\circ} \mathrm{C}$ and pressures of 0.01 atm (Beck-Winchatz and Hike 2015). The excitement of launching balloons into near-space; the challenge of authentic, hands-on science; and the use of technology such as microcontrollers, miniature sensors, radio communication systems, and HD cameras naturally draws students into scientific inquiry (Larson et al. 2009). Each step in launching a balloon is exciting and deeply rooted in real-world problem solving. 
Payload experiments can range from the simple to the fascinatingly complex. Launching, tracking, and recovering a high-altitude balloon and its payload require a set of skills that are important for success in any career (Coleman and Mitchell 2014). The experience is especially good at fostering teamwork, planning, and communication (see Figures 2 and 3).

A key feature of the research experience was that students were the primary drivers of their projects. Although faculty provided broad topics for exploration, students proposed the experimental questions and designed the experiments to answer them. This resulted in a range of projects being pursued in the HAB-Lab and a rich opportunity for both students and faculty to stretch their knowledge of science. The following are a few examples of student projects, all of which were driven by teams of two to five students. Most students worked on more than one project.

\section{Plants in Space}

This project investigated the effects of near-space radiation on plant growth. Students sent a cache of Wisconsin Fast Plant seeds on a balloon flight along with a radiation detector. When the seeds were recovered, they were planted alongside a set of controls. Plant growth was monitored, and differences in plant morphologies were recorded. The irradiated plants were more likely to exhibit twisted versus straight stems and expressed different amounts of chlorophylls $\mathrm{a}$ and $\mathrm{b}$ in their leaves at a significance level very close to $p=0.05$.

\section{Sky Glow}

This project measured light pollution as a function of altitude. Students picked an evening with a new moon and planned a flight path that would go over a small suburban town. They built a light detector using LEDs and a Raspberry Pi microcontroller, and measured the decay in urban light as the balloon ascended.

\section{Speed of Sound}

This project integrated an ultrasonic sensor and an Arduino microcontroller to measure the speed of sound during balloon ascent. Many factors (e.g., temperature, pressure, humidity) influence the speed of sound and all of them change as a function of altitude. The collected data were compared to predicted results based on models.

\section{Radio Communications}

A large team of students was interested in using Raspberry Pis and XBee RF modules to transmit data between a sensor on the balloon and a ground station in the chase van. This was technically challenging, and it was several weeks before students could successfully transmit data. On the final flight of the summer, they maintained radio contact with their sensor up to an altitude of 70,000 feet, well beyond the manufacturer's expectations.

\section{FIGURE 1. A Balloon's Eye View of the Earth}

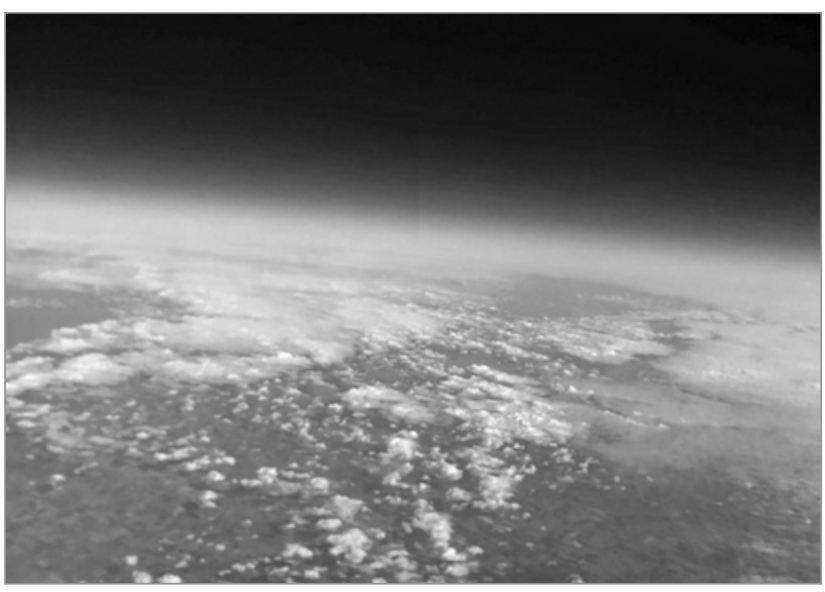

This photo was taken with a Raspberry Pi camera near a peak altitude of 98,000 feet. The curvature of the earth and the haze of the atmosphere are apparent.

\section{FIGURE 2. Preparing for a Launch}

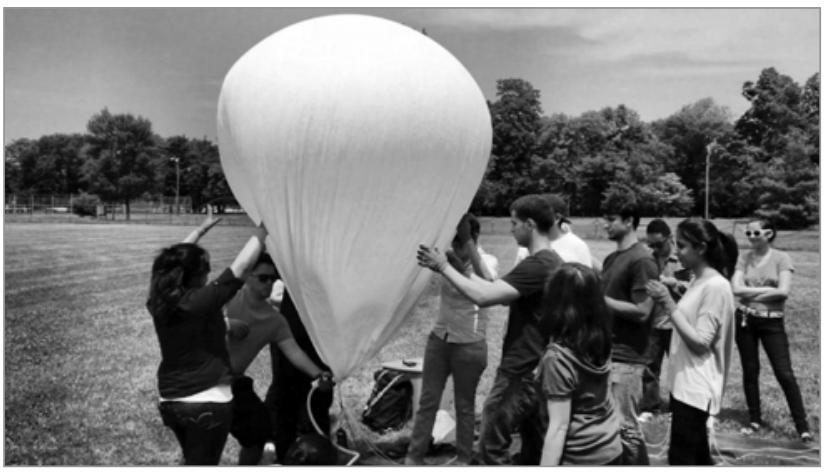

Students worked together to carefully fill a latex balloon with helium gas from a compressed gas cylinder. Once full and released, it carried its scientific payload upward at a rate of 1,000 feet per minute.

\section{FIGURE 3. Flight Paths, Predicted and Actual}

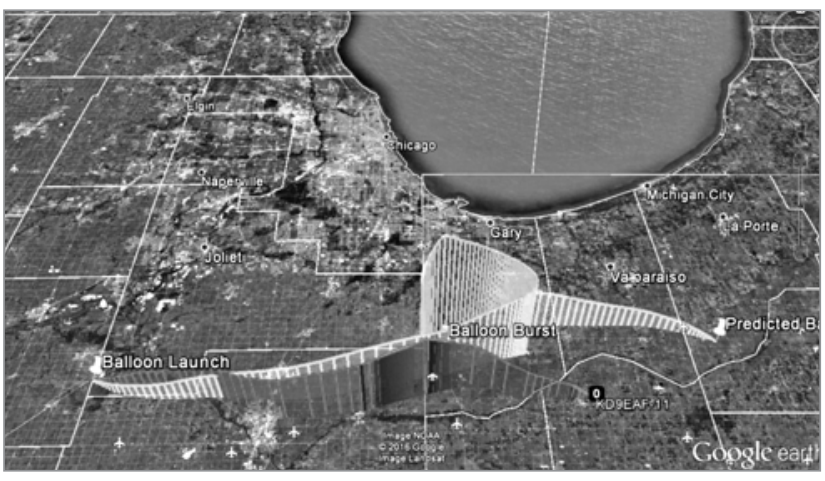

During the week leading up to a balloon launch, students used a modeling program to predict the flight path. They selected a launch site based on a projected landing site, trying to avoid lakes, forests, and heavily populated areas. To reach the landing site before the payload, students had to think on their feet. 


\section{The Challenges of Research at a Community College}

The project faced the common challenges of time, space, and resource limitations. At CCC, full-time faculty are expected to teach high-enrollment courses and have a 15-contact-hour teaching load each semester. In the STEM disciplines, this translates to three to five courses per semester. Faculty may (and usually do) teach an additional six contact hours of overload. There also are service requirements at the department, college, and district levels including registration duties, academic guidance, and curriculum review. Finally, tenure and promotion considerations put a premium on teaching and service rather than scholarship. All of this can make it difficult to find time for research and related activities with students.

With the funds and the prestige provided by the HAB grant, it was possible to provide summer support to faculty. For students, grant funds paid a summer stipend that was competitive with a summer job and provided academic-year tuition and fees. These supports freed students from having to seek outside employment to support themselves and, sometimes, their families.

Another challenge was finding a work space. As a teaching institution, CCC does not have dedicated spaces for research that can handle 15 or more students and their projects. Luckily, Truman College (a CCC on Chicago's north side) had a physical sciences laboratory that was not being used due to recent renovations. This area became the HAB-Lab and was completely dedicated to the project. It became a popular place, and it usually took some effort to get students to leave in the evening.

\section{Approach to Building a Student Cohort}

In building the two student cohorts, both the best and brightest and the "diamonds in the rough" (students who might need more focused attention to unlock their full potential) were considered. Selection criteria included U.S. citizenship (mandated by NASA), a GPA of 3.0 (although this was flexible, given the emphasis on finding untapped talent), successful completion of college algebra (or higher), successful completion of at least one majorslevel science course, and enrollment in an associate in science degree plan. In addition, students were asked to complete essays describing their academic goals and career plans. Each student had to provide contact information for two potential recommenders, who were independently contacted for information regarding the student's maturity level and ability to work with others.

Google Forms were used to collect student applications, and it was made clear that there would be a minimum commitment of 27 hours per week. This included time in the HAB-Lab, training in HAB operations, and weekly balloon launches in downstate Illinois. Since the project period overlapped with summer session, students were advised not to enroll in summer classes.

For the summer 2015 cohort, recruiting was done through faculty and advisers. Since HAB was new to the college, it took many one-on-one conversations to make students aware of the program and its benefits. After that, past participants acted as recruiters and excitement about the program grew. In summer 2015, 18 students were accepted and 16 retained (56 percent female and 61 percent underrepresented ethnicities). In summer 2016, 20 were accepted and 18 retained (44 percent female and 61 percent underrepresented ethnicities).

\section{Structure of the Research Experience}

The research started in earnest during the first week of summer semester, and a routine was quickly established. This helped students as well as faculty balance their lives and outside obligations. A typical week consisted of lab work, group meetings, and seminars Monday through Wednesday; launch preparations on Thursday; and balloon launch and retrieval all day on Friday. Luckily, the weather was cooperative. No launches needed to be canceled or rescheduled.

The HAB-Lab turned out to be the greatest asset. The lab was open from 9:00 a.m. to 6:00 p.m. during the week and was always staffed by at least one full-time faculty member. Students could come and go during that time. It quickly became obvious that there was a morning group and an afternoon group. The HAB-Lab was allowed to be untidy, and experiments could be left out for hours or days as students worked on them and tinkered. This differed from the common $\mathrm{CCC}$ student lab experience that encompasses a two-hour period for experiment set-up, experiment completion, and equipment storage. As one student said, "If you give students a lab, they become scientists. No instruction required."

\section{Professional Development and Community Activities}

On Wednesdays, seminars with faculty and other experts from the Chicago area were scheduled. These were brief and focused on specific topics such as Python programming, 3D printing, circuitry, the Earth's upper atmosphere, and statistical analysis of data. Field trips to community maker spaces and a visit to Google's Chicago office were set up. During the latter trip, students were taught about machine learning by Google engineers before going on a facilities tour. This trip was so popular that students contacted Google and set up another tour for CCC students during the academic year (see Figure 4).

During summer 2015, students had the opportunity to attend the annual Academic High Altitude Conference 
FIGURE 4. CCC Students Visit Google's Chicago Headquarters

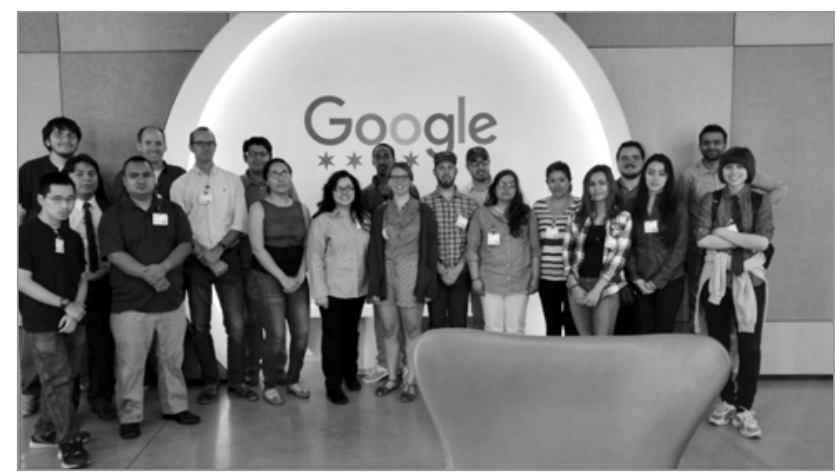

Students were taught about machine learning by Google engineers and took an exciting tour through an iconic office.

FIGURE 5. Students Represent CCC at the 2015 Google Geek Street Fair

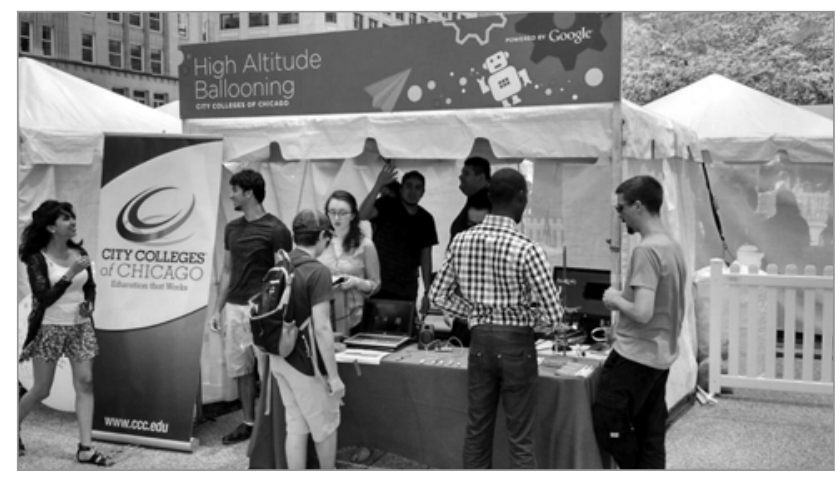

At this community event, students discussed their projects, displayed their experiments, and built a camera that would automatically take and tweet photos with a \#geekstreet hashtag.

hosted by DePaul University. This conference exposed students and faculty to other HAB researchers. They learned about different design possibilities for balloons and payloads. The conference concluded with a presentation about Project Loon, which uses massive balloons to create internet hotspots in remote parts of the Southern Hemisphere. These experiences helped students realize the potential of $\mathrm{HAB}$ research and sparked interest in an academic-year student-led HAB Club.

As students became more experienced with ballooning and their projects, there were opportunities to do community outreach. Through a partnership with the Illinois Institute of Technology, rising high school seniors gathered for a Saturday STEM session. Two HAB project students were hired to assist with a tethered balloon launch that carried payloads to take pictures and measure temperature and pressure. Project students shared their experiences and showed high school students how to build an Arduino sensor and construct a foam payload container (Gertz and Di Justo 2012).
CCC also participated in the Google Geek Street Fair, a downtown mini-maker fair with an emphasis on computer science. The students inflated a small balloon and displayed their projects. One student used a Raspberry Pi to construct a camera that took pictures and tweeted them with a \#geekstreet hashtag. More than 2,000 students from around Chicago participated in this event (see Figure 5).

\section{Quantitative Assessment of Student Gains}

The report Undergraduate Research Experiences for STEM Students: Successes, Challenges, and Opportunities (National Academies 2017) contains a synthesis of current research on undergraduate research experiences, its benefits, and its pitfalls. It also outlines a research agenda and makes recommendations for future studies to improve the understanding and practice of undergraduate research. With respect to community college students, CCC's prior work on the URC project described above established the clear benefits of an early research experience to students' attitudes, career aspirations, and skill development (Higgins 2013). As part of that project, increases in students' math abilities and chemistry content knowledge also were measured (Carver et al. 2010).

To complement that work, the longevity of student impacts due to the HAB project were evaluated using the Undergraduate Research Student Self-Assessment (URSSA). URSSA is an online tool that anonymously evaluates student research outcomes in four general areas: cognitive skills, affect, program satisfaction, and aspirations for further study (Hunter et al. 2009; Weston and Laursen 2015). All assessment data were collected after getting permission from the CCC Institutional Review Board. Due to the small size of the cohorts, to ensure the anonymity of students no demographic or other potentially identifying data were collected.

The URSSA was administered to both cohorts of students simultaneously during fall 2016 to answer the question, "What impacts of undergraduate research persist?" This allowed assessment of the immediate impact of the research experience on the summer 2016 cohort and the one-year impact of the research experience on the summer 2015 cohort. Because the total number of students who participated in the assessment was small (eight for summer 2015 and ten for summer 2016), it was difficult to make meaningful statistical comparisons between cohorts. It is believed, however, that there is high heuristic value in these data.

Figure 6 and Figure 7 present the URSSA results related to cognitive gains and affect, respectively. Two trends are apparent: (1) students reported gains in all categories; and (2) there was good agreement between the two cohorts, strongly suggesting that the benefits of the research experience persist at least one year. 
FIGURE 6. Cognitive Gains Using the URSSA Instrument

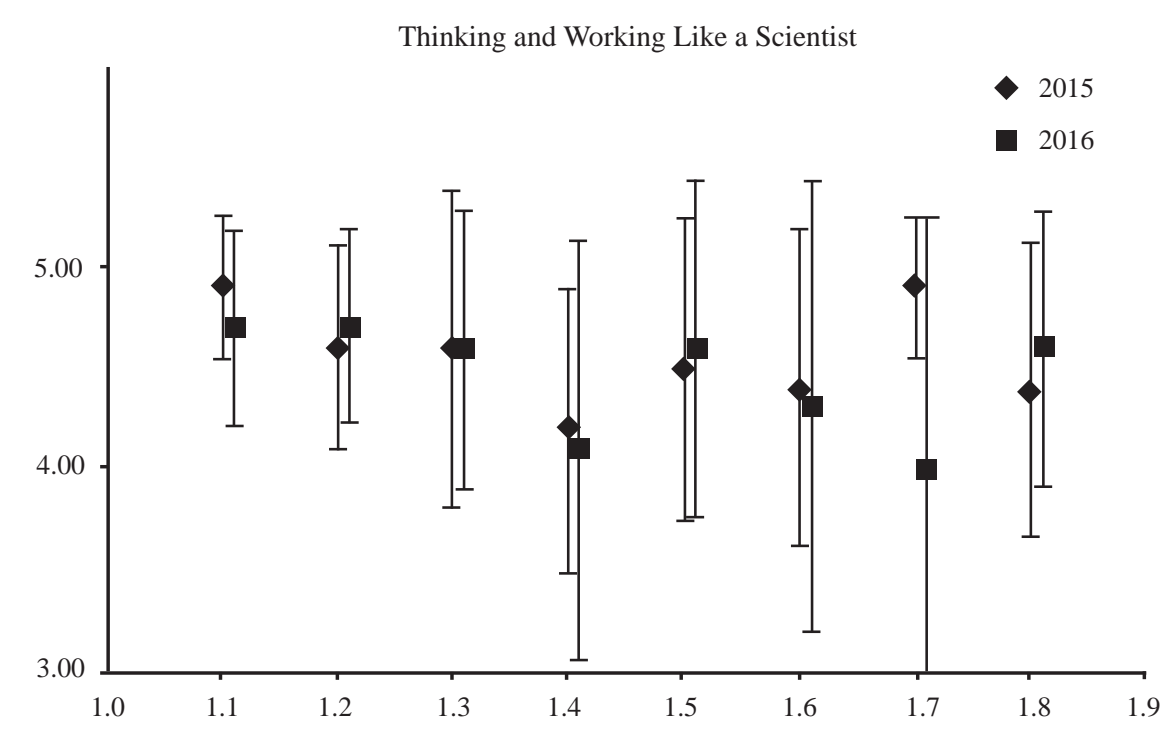

Note: Students' aggregated self-reported cognitive gains on a five-point Likert scale $(5=$ great gain, $1=$ no gain). Error bars represent one standard deviation. The $x$-axis numbers refer to the following question: How much did you gain in the following areas as a result of your most recent research experience?

1.1 Analyzing data for patterns

1.2 Figuring out the next step in a research project

1.3 Problem-solving in general

1.4 Formulating a research question that could be answered with data

1.5 Identifying limitations of research methods and designs

1.6 Understanding the theory and concepts guiding my research project

1.7 Understanding the connections among scientific disciplines

1.8 Understanding the relevance of research to my coursework

Possibly more interesting were the results related to aspirations for further study. For the question, "Compared to your intentions before doing research, how likely are you now to enroll in a $\mathrm{PhD}$ program in science, mathematics or engineering?" the 2015 cohort average was 4.0, and the 2016 cohort average was 4.5. Both results represented a "good gain" that persisted, which was consistent with the URC project assessment results. Two student quotes were especially moving: "I was already intending pursuing a $\mathrm{PhD}$, but having this experience has made me more interested in doing so," and "I am pursuing a Bioengineering degree. Wanted to stop but after doing this research program[;] it helped me want to do more and be persistent."

In fall 2017, students' longitudinal completion metrics were analyzed as another indicator of success. Results are found in Table 1. Considering only the 34 students who completed the program, 31 either earned a two-year degree or transferred to a four-year institution. Of the 3 remaining students, 2 are still active at CCC, and 1 is lost to follow-up. Although not a strictly fair comparison, these completion metrics are higher than those of the general CCC student body. CCC students overall complete degrees and transfers at rates of approximately 20 percent for each item measured.
Coupled with personal observations of the students, these data persuasively indicate that an early undergraduate research experience helped the students persist and persevere with their plans to pursue STEM careers. These data also reveal it likely that the holistic experience of the $\mathrm{HAB}$ project promoted personal growth and confidence development. Explicit indications of this were the multiple examples of students embracing informal leadership opportunities, such as arranging follow-up field trips to Google, organizing a school-supported HAB Club, and volunteering for community outreach activities such as the Google Geek Street Fair. Overall, these data illustrate that students improve their lives and achieve their dreams through the pedagogy of undergraduate research.

\section{Student Stories}

Another benefit of this project design was the amount of unstructured time that faculty members were able to spend with students, getting to know them in other ways. During these periods, remarkable changes were noted and amazing stories were told. Snapshots are presented below, anonymized to protect students' privacy. All students' names are confidential and are presented as female pseudonyms. The students showcased, however, are both male and female, and the choice of female pseudonyms 
FIGURE 7. Affective Gains Using the URSSA Instrument

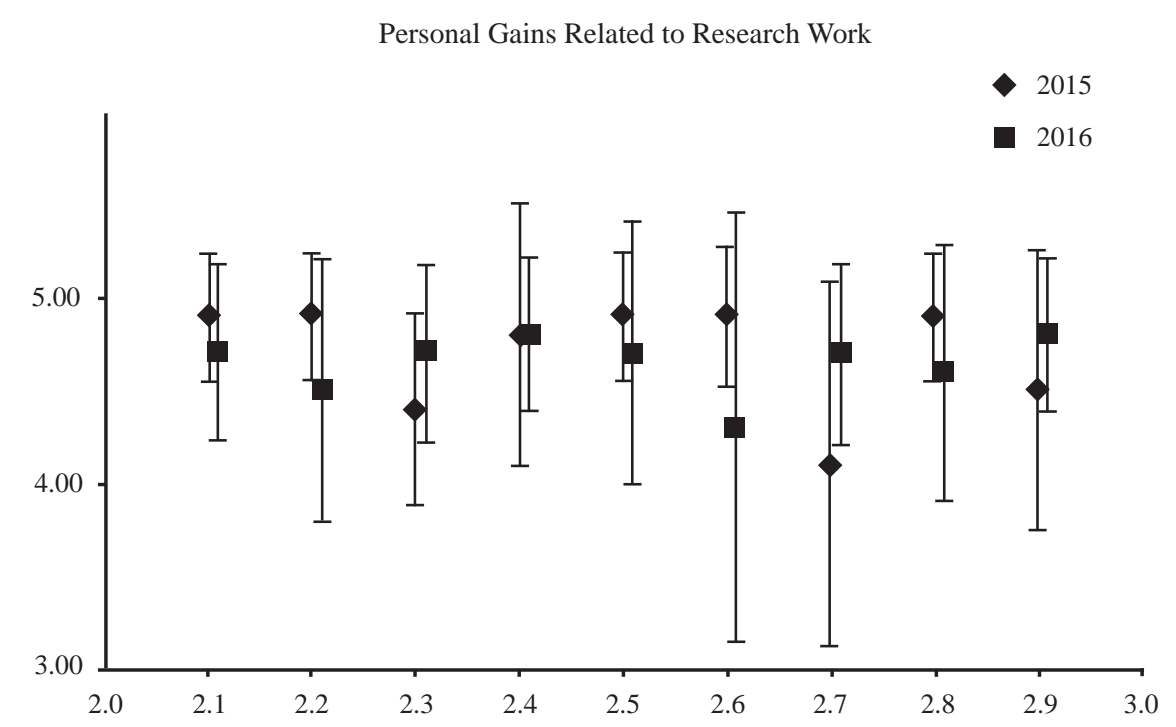

Note: Students' aggregated self-reported affective gains on a five-point Likert scale $(5=$ great gain, $1=$ no gain). Error bars represent one standard deviation. The $x$-axis numbers refer to the following question: How much did you gain in the following areas as a result of your most recent research experience?

2.1 Confidence in my ability to do research

2.2 Confidence in my ability to contribute to science

2.3 Comfort in discussing scientific concepts with others

2.4 Comfort in working collaboratively with others

2.5 Confidence in my ability to do well in future science courses

2.6 Ability to work independently

2.7 Developing patience with the slow pace of research

2.8 Understanding what everyday research work is like

2.9 Taking greater care in conducting procedures in the lab or field

TABLE 1. Longitudinal Completion Metrics as of Fall 2017

\begin{tabular}{|c|c|c|c|c|c|}
\hline Cohorts & Number & $\begin{array}{c}\text { Two-year } \\
\text { degree earned }\end{array}$ & $\begin{array}{c}\text { Transfer to } \\
\text { four-year institution }\end{array}$ & $\begin{array}{c}\text { Degree and } \\
\text { transfer }\end{array}$ & $\begin{array}{c}\text { Degree or } \\
\text { transfer }\end{array}$ \\
\hline 2015 & 16 & $11(69 \%)$ & $13(81 \%)$ & $9(56 \%)$ & $15(94 \%)$ \\
\hline 2016 & 18 & $13(72 \%)$ & $13(72 \%)$ & $10(56 \%)$ & $16(89 \%)$ \\
\hline Combined & 34 & $24(71 \%)$ & $26(76 \%)$ & $19(56 \%)$ & $31(91 \%)$ \\
\hline
\end{tabular}

should not be taken to suggest a gender-based difference in student impact.

Danielle joined the HAB project with only a minimal science background and an aptitude for technology. She left an engineering enthusiast and started a student HAB Club, which later organized multiple $\mathrm{HAB}$ launches and a visit to Google. She was offered a full scholarship to a four-year institution and is majoring in biology.

Julia brought a significant technical background to the HAB group. She was an older (nontraditional) student and often spent her time in the lab helping other students.
She worked on her own projects at home. After the HAB program, she was accepted to a local four-year institution where she majors in chemical engineering and works with a formal leadership program supporting college-bound high school students with community outreach projects.

Becky and Vanessa were featured on the evening news of the CBS affiliate in Chicago as "Super Girls," a tie-in with the recently released television series. They were interviewed about their experiences and confidently encouraged other girls to seek out experiences like their own. After her television appearance, Becky was asked to make a similar presentation to her church. The following summer, she 
participated in a Research Experience for Undergraduates project studying diabetes and has become a chemical engineering major with a generous scholarship. Vanessa is majoring in biochemistry at another four-year institution.

Lois had little programming experience when she entered the program. She worked on a second-generation sky-glow sensor that measured light as a function of altitude and eventually took over leadership of the HAB Club started by another student. In that role, she organized a student trip to Google with more than 20 participants. Later, she was selected for the NASA Community College Aerospace Scholars program at the Glenn Research Center. She worked on an interdisciplinary team to explore a business model for the next Mars Rover.

Denise brought her mother to one of the launches to share the experience. Her mother was impressed by the process and her daughter's role in it. Later, Denise was excited to show her mother her first paycheck as a working scientist. Her mother said, "I can't believe you make \$12 an hour. I only make $\$ 10$ !" This exchange was a powerful moment for the two of them and for the faculty team members.

Gretchen worked on radio communication between ground-based radio transmitters and the HAB for in-flight communication during the experiments. She was accepted for a summer internship at the Harvard-Smithsonian Center for Astrophysics where she studied solar flares using data from NASA's Interface Region Imaging Spectrometer (IRIS) spacecraft.

\section{Conclusions}

Assessment information, ongoing student feedback, and informal observations provided evidence that the primary goal of engaging community college students in authentic undergraduate research was successful. The success of the program depended on several factors: a pool of talented and eager students, the resources and prestige of the NASA grant, strong institutional support, and effective collaborations. Although this program did not fit the traditional educational model at CCC, its positive impacts were obvious to faculty and administrators, all of whom did what they could to support it. The framework put students in charge of their own work and made them act and think like professional scientists and engineers. Ownership of their projects, the HAB-Lab space, and freedom to fail and recover were likely the strongest drivers of success. It is believed that this program would not have been successful without the trust placed in the students and their ideas. For the future, plans are to sustain a culture of undergraduate research at CCC and continue to empower students through authentic inquiry.

\section{Acknowledgments}

This material is based upon work supported by NASA and the Illinois Space Grant Consortium under grant no. NNX14AR13A and the National Science Foundation under grant no. 1655042. Any opinions, findings, and conclusions or recommendations expressed in this material are those of the authors and do not necessarily reflect the views of NASA, the Illinois Space Grant Consortium, or the National Science Foundation.

\section{References}

Beck-Winchatz, Bernhard, and Nina Hike. 2015. "Near Space Science: A Ballooning Project to Engage Students Beyond the Big Screen.” Science Teacher 82(1): 29-36.

Carver, Jeffery S., Morna Brothers, and Thomas B. Higgins. 2010. "Assessment in Undergraduate Chemistry Research: Accomplishments at Harold Washington College." In Assessment of Chemistry, 75-95, ed. John Ryan, Ted Clark, and Alexis Collier. Vol. 5 of Assessment in the Disciplines. Tallahassee, FL: Association for Institutional Research.

Coleman, Jill S. M., and Melissa Mitchell. 2014. "Active Learning in the Atmospheric Science Classroom and Beyond through High-Altitude Ballooning." Journal of College Science Teaching 44(2): 26-30. doi: 10.2505/4/jcst14_044_02_26

Gertz, Emily, and Patrick Di Justo. 2012. Atmospheric Monitoring with Arduino: Building Simple Devices to Collect Data about the Environment. Sebastopol, CA: O'Reilly Media.

Higgins, Thomas B. 2013. "Undergraduate Research with Community College Students: Models and Impacts." In ACS Symposium Series 1145: Trajectories of Chemistry Education Innovation and Reform, ed. Thomas Holme, Melanie M. Cooper, and Pratibha Varma-Nelson, 171-184. Washington, DC: American Chemical Society.

Higgins, Thomas B., Bernhard Beck-Winchatz, Michael Davis, and Andrew Kruger. 2017. "Using Old Space in New Ways to Support Undergraduate Research with Community College Students." Scholarship and Practice of Undergraduate Research 1(2): 33 .

Higgins, Thomas B., Kenneth L. Brown, Jason G. Gillmore, Jeffery B. Johnson, Graham F. Peaslee, and Daniel J. Stanford. 2011. "Successful Transitions from the Two-Year College to the Four-Year College Facilitated by Undergraduate Research." CUR Quarterly 31(3): 16-22.

Hunter, Anne-Barrie, Timothy J. Weston, Sandra L. Laursen, and Heather Thiry. 2009. "URSSA: Evaluating Student Gains from Undergraduate Research in the Sciences." CUR Quarterly 29(3): 15-19.

Kuh, George D. 2008. High-Impact Educational Practices: What They Are, Who Has Access to Them, and Why They Matter. Washington, DC: Association of American Colleges and Universities.

Larson, Shane L., John C. Armstrong, and William A. Hiscock. 2009. "The First Frontier: High Altitude Ballooning as a Platform for Student Research Experiences in Science and Engineering." American Journal of Physics 77: 489-497. doi: 10.1119/1.3097775

National Academies of Sciences, Engineering, and Medicine. 2015. Integrating Discovery-Based Research into the Undergraduate Curriculum: Report of a Convocation. Washington, DC: National Academies Press. 
National Academies of Sciences, Engineering, and Medicine. 2017. Undergraduate Research Experiences for STEM Students: Successes, Challenges, and Opportunities. Washington, DC: National Academies Press.

Verhage, Paul. 2004. "Near Space, Part 1: How Some Hobbyists are Getting Around the Difficulties Associated with Amateur Space Exploration." Nuts and Volts 25(2): 64-69.

Weston, Timothy J., and Sandra L. Laursen. 2015. "The Undergraduate Research Student Self-Assessment (URSSA): Validation for Use in Program Evaluation." CBE-Life Sciences Education 14(3): 1-10. doi: 10.1187/cbe.14-11-0206

\section{Thomas B. Higgins}

Harold Washington College, tbhiggins@ccc.edu

Thomas B. Higgins is a professor of chemistry at Harold Washington College. He was a principal investigator of the HAB project. He served as a Councilor in the CUR Chemistry Division from 2012 to 2015. Higgins was a rotating program officer in the Division of Undergraduate
Education of the National Science Foundation from August 2015 to August 2017.

Bernhard Beck-Winchatz is a professor of physics and STEM studies at DePaul University. He is the DePaul campus director of the Illinois Space Grant Consortium and has been launching weather balloons with his students since 2009. He was a principal investigator of the $H A B$ project.

Michael Davis is a department chair and professor of natural science at St. Petersburg College. He was a principal investigator of the HAB project while he was an associate professor of chemistry at Truman College.

Andrew Kruger is an assistant professor of physics at Wilbur Wright College. He also is a project assistant in the Adler Planetarium's Far Horizons Project, a high-altitude ballooning project, and teaches an independent research course in which students develop projects for ballooning. He was a principal investigator of the HAB project.

\section{Creating Collaborative Connections in and through Undergraduate Research}

\section{CUR Conference 2018 Hyatt Regency Crystal City, VA}

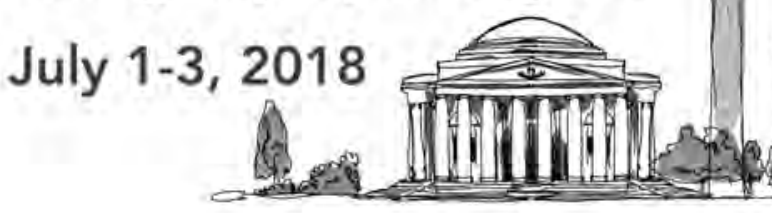

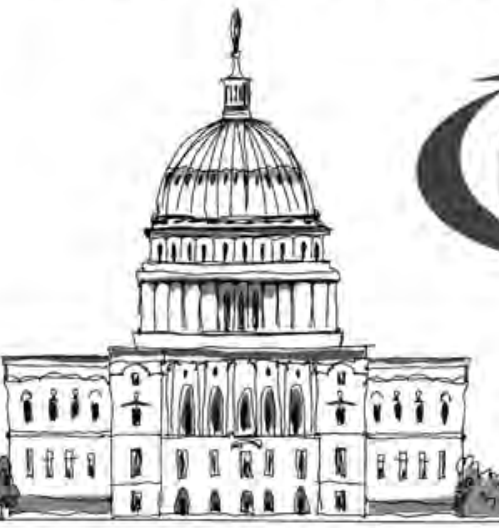
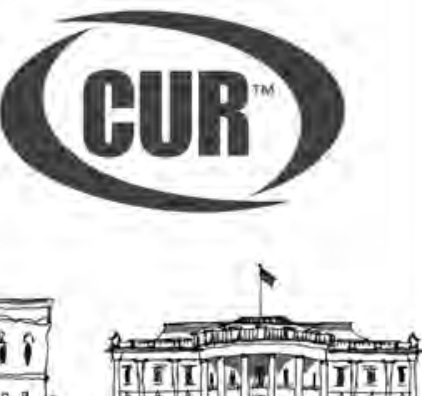

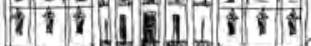

For more information about the CUR Conference, please visit: http://bit.ly/2018CURBiennial 